NASA/TM-2004-212942

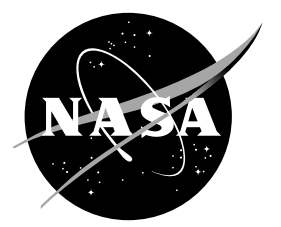

Non-Deterministic Dynamic Instability of Composite Shells

Christos C. Chamis

Glenn Research Center, Cleveland, Ohio

Galib H. Abumeri

QSS Group, Inc., Cleveland, Ohio 
Since its founding, NASA has been dedicated to the advancement of aeronautics and space science. The NASA Scientific and Technical Information (STI) Program Office plays a key part in helping NASA maintain this important role.

The NASA STI Program Office is operated by Langley Research Center, the Lead Center for NASA's scientific and technical information. The NASA STI Program Office provides access to the NASA STI Database, the largest collection of aeronautical and space science STI in the world. The Program Office is also NASA's institutional mechanism for disseminating the results of its research and development activities. These results are published by NASA in the NASA STI Report Series, which includes the following report types:

- $\quad$ TECHNICAL PUBLICATION. Reports of completed research or a major significant phase of research that present the results of NASA programs and include extensive data or theoretical analysis. Includes compilations of significant scientific and technical data and information deemed to be of continuing reference value. NASA's counterpart of peerreviewed formal professional papers but has less stringent limitations on manuscript length and extent of graphic presentations.

- TECHNICAL MEMORANDUM. Scientific and technical findings that are preliminary or of specialized interest, e.g., quick release reports, working papers, and bibliographies that contain minimal annotation. Does not contain extensive analysis.

- CONTRACTOR REPORT. Scientific and technical findings by NASA-sponsored contractors and grantees.
- CONFERENCE PUBLICATION. Collected papers from scientific and technical conferences, symposia, seminars, or other meetings sponsored or cosponsored by NASA.

- SPECIAL PUBLICATION. Scientific, technical, or historical information from NASA programs, projects, and missions, often concerned with subjects having substantial public interest.

- TECHNICAL TRANSLATION. Englishlanguage translations of foreign scientific and technical material pertinent to NASA's mission.

Specialized services that complement the STI Program Office's diverse offerings include creating custom thesauri, building customized databases, organizing and publishing research results ... even providing videos.

For more information about the NASA STI Program Office, see the following:

- Access the NASA STI Program Home Page at http://www.sti.nasa.gov

- E-mail your question via the Internet to help@sti.nasa.gov

- Fax your question to the NASA Access Help Desk at 301-621-0134

- Telephone the NASA Access Help Desk at 301-621-0390

- Write to:

NASA Access Help Desk

NASA Center for AeroSpace Information 7121 Standard Drive

Hanover, MD 21076 
NASA/TM-2004-212942

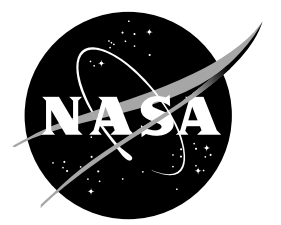

Non-Deterministic Dynamic Instability of Composite Shells

Christos C. Chamis

Glenn Research Center, Cleveland, Ohio

Galib H. Abumeri

QSS Group, Inc., Cleveland, Ohio

Prepared for the

44th Structures, Structural Dynamics, and Materials Conference

cosponsored by the AIAA, ASME, ASCE, and AHS

Norfolk, Virginia, April 7-10, 2003

National Aeronautics and

Space Administration

Glenn Research Center 
This work was sponsored by the Low Emissions Alternative Power Project of the Vehicle Systems Program at the NASA Glenn Research Center.

Available from

NASA Center for Aerospace Information 7121 Standard Drive

Hanover, MD 21076
National Technical Information Service 5285 Port Royal Road Springfield, VA 22100

Available electronically at http:/ /gltrs.grc.nasa.gov 


\title{
Non-Deterministic Dynamic Instability of Composite Shells
}

\author{
Christos C. Chamis \\ National Aeronautics and Space Administration \\ Glenn Research Center \\ Cleveland, Ohio 44135 \\ Galib H. Abumeri \\ QSS Group, Inc. \\ Cleveland, Ohio 44135
}

\begin{abstract}
A computationally effective method is described to evaluate the non-deterministic dynamic instability (probabilistic dynamic buckling) of thin composite shells. The method is a judicious combination of available computer codes for finite element, composite mechanics and probabilistic structural analysis. The solution method is incrementally updated Lagrangian. It is illustrated by applying it to thin composite cylindrical shell subjected to dynamic loads. Both deterministic and probabilistic buckling loads are evaluated to demonstrate the effectiveness of the method. A universal plot is obtained for the specific shell that can be used to approximate buckling loads for different load rates and different probability levels. Results from this plot show that the faster the rate, the higher the buckling load and the shorter the time. The lower the probability, the lower is the buckling load for a specific time. Probabilistic sensitivity results show that the ply thickness, the fiber volume ratio and the fiber longitudinal modulus, dynamic load and loading rate are the dominant uncertainties in that order.
\end{abstract}

\section{Introduction}

Shell structures are in general very efficient structural components for resisting combined loading conditions. Examples of their use are aircraft fuselages, submarine hulls and space launch vehicles and many others for transportation and storage. Cylindrical shells made from composites utilize composites most effectively. Thin shells are susceptible to buckling when subjected to compressive static loads. In more aggressive loading environments, they may also be subjected to dynamic or time dependent loads. Predicting the resistance of thin shells to buckling is a rather difficult task because of the simplifying assumptions that need to be made in order to obtain results that may be representative of the physical situation. The advent of the finite element method has overcome many of the difficulties associated with the shell boundary conditions, loadings and geometric configuration. The finite element method has also made possible the evaluation of the buckling load of thin composite shell under dynamic loading.

These predictions are generally obtained by assuming that all the values of the variables associated with the buckling of composite shell are fixed and neglect any variability. For more realistic predictive values, it is important to account for variations of those variables. One way to account for the variability is to perform probabilistic evaluation of dynamic buckling. Deterministic evaluation of the buckling of composite shells has been recently performed as described in reference 1, where relevant references are also cited. Probabilistic buckling of composite shell has been evaluated as described in reference 2 . However, probabilistic evaluation of the dynamic buckling of shells has not been performed as of this writing. Therefore, the objective of this investigation is to describe one approach that has been successfully used to perform probabilistic dynamic buckling of composite shells. A secondary specific objective and centerpiece to the approach was to use conventional finite elements, available composite 
mechanics and elementary probabilistic methods. In essence, the approach consists of the judicious combination and use of all three and coupled with incremental updated Lagrangian solution algorithm. This is done in an incremental fashion starting with $\mathrm{t}=0$ with the first load increment. In subsequent time increments, the geometry, properties and responses are updated by using local iteration for global structural convergence. The process is repeated until the applied load is reached. The emphasis of the investigation was on developing the method and demonstrating its effectiveness by using a cylindrical composite thin shell. The authors recognize that the how part of the solutions is not unique and that other methods could be used. The authors' objective was to develop a method that is generic and not restrictive to any class of problems or conditions. The authors believe that the method developed and described meets and perhaps exceeds those objectives.

\section{Fundamental Considerations}

The governing equation for dynamic structural response in matrix form is

$$
[M]\{\ddot{\mathrm{u}}\}+[C]\{\dot{u}\}+[K]\{u\}=\{F(t)\}
$$

where $\mathrm{M}$ is the mass; $\mathrm{C}$ is the damping; $\mathrm{K}$ is the stiffness and $\mathrm{F}$ is the forcing function; $\ddot{\mathrm{u}}$ is the acceleration, $\dot{u}$ is the velocity and $u$ is the displacement. Equation (1) is of generic form and represents the single or multi-degrees of freedom structures. Dynamic buckling is obtained by solving equation (1) as a linear eigen value problem or as a large displacement amplitude problem by using the updated Lagrangian method. Available structural analysis finite element computer codes/programs have both options (ref. 3). The linear eigen value approach is usually referred to as the frequency domain. The large amplitude is usually referred to as the time domain. The approach (method) used herein and is described subsequently uses combinations of both. The usual approach for the frequency domain is to assume a transcendental function for the displacements; substitute those displacements in equation (1) and then solve it by the use of various eigen values extraction routines (ref. 3). In the time domain the usual approach is to express the displacements in equation (1) in finite difference form and then solve the equation by incrementing the time. In this approach, updates for material properties, temperature changes, geometric deformations and structural damage are readily incorporated as they occur in time. This approach is often referred to as the updated Lagrangian, as was mentioned earlier. A combined capability of at least multidisciplinary composite mechanics, dynamic structural analysis and probabilistic simulation methods are needed to evaluate probabilistic dynamic buckling of composite shell structures. The one used for this investigation is called EST/BEST for Engine Structures Technology/Benefits ESTimator (ref. 4). It is noted that EST/BEST consists of discipline modules which are integrated into a stand-alone computer program by soft coupling. The modules that were used to evaluate the probabilistic structural dynamic buckling of composite shells will be described as each of these modules is used in the evaluation.

\section{Deterministic Dynamic Buckling of a Composite Shell}

The specific shell evaluated is depicted schematically in figure 1 where the material and loading conditions are also shown. The undampened version of equation (1) can be expressed as follows:

$$
\begin{gathered}
\{\ddot{\mathrm{u}}\}=[M]^{-1}\{F(t)\} \\
\{\dot{\mathrm{u}}\}=\Delta T\{\ddot{\mathrm{u}}\} \quad ;\{\mathrm{u}\}=\Delta T^{2}\{\ddot{u}\}
\end{gathered}
$$


Equation (2) expresses the dynamic equilibrium requirements of the structure at each time increment. At the end of each time increment: (1) equilibrium is attained by local iteration, and (2) the structural geometry is updated to include displacements that are caused by the imposed dynamic loading. The results obtained from solving the undampened version of equation (1) at $t=0$ by direct time integration are shown in figure 2 for loaded-end axial acceleration; in figure 3 for the corresponding velocity; and in figure 4 for the corresponding incremental displacement. It is instructive to examine the results shown in figures 2 to 4 . There is considerable fluctuation in the acceleration from about -150000 to $300000 \mathrm{in} . / \mathrm{sec}^{2}$ initially and decreases monotonically with time to near zero. The only explanation at this time about the intermediate fluctuations is interactions with either radial or circumferential acceleration responses. The velocity plotted in figure 3 is also oscillatory varying from about 5 to $<50 \mathrm{in}$./ $\mathrm{sec}$ initially. The velocity is smooth compared to the acceleration and appears to approach a value of $25 \mathrm{in} . / \mathrm{sec}$. The incremental end displacement (axial shell shortening) plotted in figure 4 is also oscillating from 0.004 to $0.01 \mathrm{in}$. The oscillatory behavior is more predominant at early times as can be seen in figure 5 it decays very rapidly approaching a value of about $0.007 \mathrm{in}$. The effects of the total time for the same total load are evident in figure 5 where the two rates differ by 1 decade.

The dynamic buckling load is obtained at each time step by first satisfying equation (1), including iteration when necessary, and then solve for the buckling load from the equation:

$$
([K]-[F(t)]\{u\})=\lambda^{2}\{u\}
$$

where equation (3) is solved by available eigen value extraction routines in conventional structural analysis computer codes, such as IPACS (ref. 5) module. The buckling load predicted by using equation (3) versus incremented dynamic load is shown in figure 6. As can be seen, the dynamic buckling load decreases monotonically approaching asymptotically a value that is about 30 percent of the static value (at $\mathrm{t}=0)$. The time dependent dynamic buckling load and applied dynamic load are plotted in figure 7. The plot shows that the shell-buckling load decreases as the dynamic load increases. The graph in figure 7 suggests that superimposing the increasing dynamic force in the same graph with the dynamic buckling load, the dynamic buckling load can be determined from the intersection of the two curves. This is illustrated graphically in figure 7 . The authors consider the results in figure 7 as demonstration of a straightforward procedure to evaluate dynamic buckling loads of composite shell structures by using available general purpose structural analysis, finite element and composite mechanics computer codes.

The approach is not limited to linearly incremented dynamic loads, although the authors have not checked it for nonlinearly incremented loads or for "suddenly" $(\mathrm{t} \approx 0)$ loads. The corresponding buckled shapes of the shell are shown in figure 8(a) for the static load and in figure 8(b) for the dynamic load prior to ply failures. It is interesting to observe that the buckled shape of the shells is about the same, relative to the number of waves especially around the circumferences. The amplitudes are different, as would be expected. The other notable observation in figure 8 is that most of the buckled activity dominates the middle part of the shell. It is seen from equation (3) that a shell-buckling load exists for any dynamic load magnitude greater than zero. In the next section, the computer code used for the probabilistic dynamic buckling analysis is described in some details.

\section{Description of the Ipacs Computer Code}

The probabilistic dynamic buckling analysis is performed using the integrated probabilistic assessment of composite structures computer code IPACS (refs. 5 and 6). With the direct coupling of composite mechanics, including interply and intraply hybrids using the integrated composite analyzer computer code ICAN (ref. 7), finite element structural analysis MHOST (ref. 8), and probabilistic methods, IPACS is capable of simulating uncertainties in all inherent scales of the composite, from constituent materials to the composite structure and its loading conditions. The evaluation process starts 
with the identification of the primitive variables at the micro and macro composites scales including fabrication. These variables are selectively perturbed in order to generate a database for the determination of the relationships between the desired materials behavior and/or structural response and the primitive variables.

The composite micro-mechanics is used to carry over the scatter in the primitive variables to the ply and laminate scales (steps A and B in fig. 9). Laminate theory is then used to determine the scatter in the material behavior at the laminate scale (step C). This step leads to the perturbed resultant force/momentdisplacement/curvature relationships used in the structural analysis. Next, the finite element analysis is performed to determine the perturbed structural responses corresponding to the selectively perturbed primitive variables (step D). This completes the description of the hierarchical composite material/structure synthesis shown on the left side of figure 9 . The multi scale progressive decomposition of the structural response to the laminate, ply, and fiber-matrix constituent scales is shown on the right side of figure 9 (steps E to G). After the decomposition, the perturbed fiber, matrix, and ply stresses can be determined. An important feature of IPACS, depicted at the bottom of figure 9, is the nonlinear multifactor interaction model for computing the fiber-matrix constituent material properties, including the effects of the prevailing service environments.

Next, the fast probability integrator (FPI) (ref. 9) code is used to determine the functional relationship between the response and the primitive variables. The cumulative distribution function of the response is then calculated with the numerically determined functional relationship and the known probability density functions of the primitive variables. The sensitivity factors of the primitive variables to each response's cumulative probability are also determined. This information is crucial for the reliability assessment.

\section{Probabilistic Dynamic Buckling of a Composite Shell}

The probabilistic evaluation of the composite cylindrical shell was performed by using an integrated computer code (IPACS) Integrated Probabilistic Assessment of Composite Structures (refs. 5 and 6). The information in table 1 is used as input to IPACS computer code. With available standard deviations for the various primitive variables, the coefficient of variation $(\mathrm{COV})$ was determined by dividing the standard deviation by the mean. The probabilistic composite mechanic module generates the properties at each node of the finite element model of the structure. This information is used by probabilistic composite mechanics to generate 42 probabilistic variable properties that are needed to probabilistically describe the composite laminate at each finite element node. The probabilistic variables include fiber and matrix properties, and fabrications variables. These properties are subsequently combined with the structural probabilistic information to probabilistically describe the composite shell as shown at the top of figure 9.

The cumulative probability distribution function generated IPACS of the dynamic buckling load is plotted in figure 10. The comparable static buckling load is also shown in figure 10 for comparison purposes. As can be observed, at 50 percent probability, the probability dynamic buckling load is about one-half of the static buckling load as would be expected from equation (3). It is also observed that the dynamic buckling load at 0.5 probability is the same as that in figure $8(\mathrm{~b})$, as should be since both are obtained by using the mean values of the input data. Another observation in figure 10 is that the dynamic buckling load of the shell may vary from about 700 kips at very low probability to about 3000 for high probability. This is a very large variation and may indicate the difficulty of evaluating dynamic buckling loads experimentally.

The corresponding sensitivities of the factors affecting buckling loads for 1/1000 and 999/1000 are shown in figure 11 for static buckling load and in figure 12 for dynamic buckling load. Comparing these two figures, it is seen that the dynamic load affects the shell buckling load while the static load does not. The shell geometry (length, radius and the laminate configuration) has negligible effects while the ply 
(shell) thickness and the fiber volume ratio have major effects. Note that the sensitivity of the ply thickness is increased at high probability (about 15 percent) compared to that at low probability. The sensitivity of the fiber volume ratio is decreased at high probability. The changes in the sensitivity are attributed to the fact that the buckling load is more sensitive to the shell thickness than to fiber volume ratio. Therefore, when buckling is likely to occur, the ply thickness effect is increased as compared to that of the fiber volume ratio. The deformed shell shapes at those three probabilities are plotted in figure 13 for the dynamic case. The shapes appear to be the same but with different displacement amplitudes, as those in figure 8.

The dynamic end accelerations are plotted in figure 14 for the three different probabilities; in figure 15 for the velocities, and in figure 16 for the displacements. As expected and as mentioned previously, the amplitudes of these responses are smaller for the larger probabilities since they represent a stiffer shell for the same load. Note in figure 14 the same fluctuations that were observed in figure 2.

A universal plot can readily be developed for the probabilistic buckling load for a specific shell but subjected to different dynamic loading rates and at different probability levels. This type of plot is illustrated in figure 17. The loading increments are equal resulting in linear dynamic load rate. They can just as easily be unequal and thereby accommodate a variety of rates. Note that the two different rates 4000 kips and 2000 kips are at 0.5 probability. The higher rate increases the buckling load and occurs at a shorter time. The lower rate decreases the buckling load and occurs at a longer time.

The afore-discussion leads to the conclusion that probabilistic dynamic buckling of composite shell structures can be evaluated by a capability that integrates (1) dynamic structural analysis, (2) composite mechanics, and (3) probabilistic concepts. As was demonstrated in the probabilistic evaluation for the dynamic buckling of a composite shell, that capability appears to be sufficient and efficient since it relies on proven and readily available methods.

\section{Summary of Results}

The salient results of an investigation to develop an effective method for the probabilistic dynamic buckling of thin composite shells are as follows: (1) The method was developed and consists of the judicious combination of conventional finite element method, available composite mechanics, elementary probabilistic mechanics and incrementally updated Lagrangian solution algorithm; (2) The method is generic and not restricted to any special class of shells and/or loading conditions; (3) The effectiveness of the method is demonstrated to evaluate the probabilistic dynamic buckling load of a specific thin composite shell; (4) Typical results obtained include deterministic and probabilistic dynamic buckling, buckling modes, affects of uncertainties and respective sensitivities; (5) A universal plot is developed which shows the buckling load at different probability levels and at different loading rates; and (6) The authors consider the method easy to apply and to their knowledge the first of its kind.

\section{References}

1. X. Huyan and G.J. Simitses, Dynamic Buckling of Imperfect Cylindrical Shells Under Axial Compression and Bending Moment. AIAA Journal. Vol. 35, No. 8, August 1997.

2. M.C. Shiao and C.C. Chamis, A Probabilistic Buckling Design of Stiffened Composite Structures with Cutouts. $10^{\text {th }}$ DoD/NASA/FAA Conference, November 1993.

3. MSC NASTRAN 2001-Quick Reference Guide. MSC Software Corporation, Los Angeles, CA, 2001.

4. G.H. Abumeri and C.C. Chamis, EST/BEST A Computer Code for Assessing the Benefits of Advanced Aerospace Technologies. Elsevier, Advances in Engineering Software. Vol. 28, No. 4, June 1997.

5. Chamis, C.C. and Shiao, M.C., IPACS-Integrated Probabilistic Assessment of Composite Structures: Code Development and Applications. Third NASA Advanced Composite Technology Conference, Vol. 1, Pt. 2, NASA CP-3178-VOL-1-PT-2, 1993, pp. 987-999. 
6. C.C. Chamis, Probabilistic Composite Design. American Society for Testing and Materials, October 1997.

7. P.L.N. Murthy and C.C. Chamis, Integrated Composite Analyzer (ICAN):Users and Programmers Manual, NASA Technical Paper 2515, 1986.

8. S. Nakazawa, J.B. Dias, and M.S. Spiegel, The MHOST Finite Element Program: 3-D Inelastic Analysis Methods for Hot section Components: Volume II-User's Manual, NASA Contractor Report $182235,1989$.

9. Wu, Y.-T., Demonstration of a New Fast Probability Integration Method for Reliability Analysis, Advances of Aerospace Structural Analysis, ASME, pp. 63-73, 1985. 
Table 1. Probabilistic Dynamic Buckling of a Composite Shell Primitive Variables, Scatter, Standard Deviation and Distribution

\begin{tabular}{|c|c|c|c|c|c|c|}
\hline$\underline{\text { Primitive Variable }}$ & $\underline{\text { Low }}$ & $\underline{\text { Mean }}$ & $\underline{\text { High }}$ & $\frac{\text { Coefficient }}{\underline{\text { of Variation }}}$ & $\frac{\text { Standard }}{\text { Deviation }}$ & $\frac{\text { Probabilistic }}{\text { Distribution }}$ \\
\hline Fiber Volume Ratio & 0.585 & 0.65 & 0.715 & $\pm 10 \%$ & 0.065 & Normal \\
\hline Void Volume Ratio & 0.0425 & 0.050 & 0.0575 & $\pm 15 \%$ & 0.0075 & LogNormal \\
\hline Outer Ply Angle $\left(45^{\circ}\right)$ & 42.0 & 45.0 & 48.0 & $\pm 6.66 \%$ & 3.0 & Normal \\
\hline Outer Ply Angle $\left(-45^{\circ}\right)$ & -42.0 & -45.0 & -48.0 & \pm 6.66 & 3.0 & Normal \\
\hline Outer Ply Angle $\left(0^{\circ}\right)$ & -3.0 & 0.0 & 3.0 & $\pm 3.0 \%$ & 3.0 & Normal \\
\hline Outer Ply Angle $\left(90^{\circ}\right)$ & 87.0 & 90.0 & 93.0 & $\pm 3.33 \%$ & 3.0 & Normal \\
\hline Ply Thickness (in.) & 0.0045 & 0.005 & 0.0055 & $\pm 5 \%$ & 0.00025 & LogNormal \\
\hline Fiber Modulus Ef11 (msi) & 26.35 & 31.0 & 35.65 & $\pm 5 \%$ & 1.55 & Normal \\
\hline Fiber Shear Modulus Gf12 (msi) & 1.8 & 2.0 & 2.2 & $\pm 10 \%$ & 0.20 & Normal \\
\hline Matrix Modulus Em (msi) & 0.45 & 0.50 & 0.550 & $\pm 10 \%$ & 0.05 & Normal \\
\hline Fiber Density $\left(\mathrm{lb} / \mathrm{in}^{3}\right)$ & 0.0567 & 0.0630 & 0.0693 & $\pm 10 \%$ & 0.0063 & LogNormal \\
\hline Matrix Density $\left(\mathrm{lb} / \mathrm{in}^{3}\right)$ & 0.03987 & 0.0443 & 0.04873 & $\pm 10 \%$ & 0.00443 & LogNormal \\
\hline Loading Rate (sec) & $2.375 \mathrm{E}-4$ & $42.5 \mathrm{E}-4$ & $2.625 \mathrm{E}-4$ & $\pm 5 \%$ & $1.25 \mathrm{E}-5$ & LogNormal \\
\hline Initial Dynamic Load (kips) & 18.0 & 20.0 & 22.0 & $\pm 10 \%$ & 2.0 & Normal \\
\hline Length (in.) & 59.0 & 60.0 & 61.0 & $\pm 1.67 \%$ & 1.0 & Normal \\
\hline Diameter (in.) & 29.5 & 30.0 & 30.50 & $\pm 1.67 \%$ & 0.50 & Normal \\
\hline
\end{tabular}

Graphite Epoxy Composite: $\left[(45,-45,0,90)_{7},-45,45\right]$

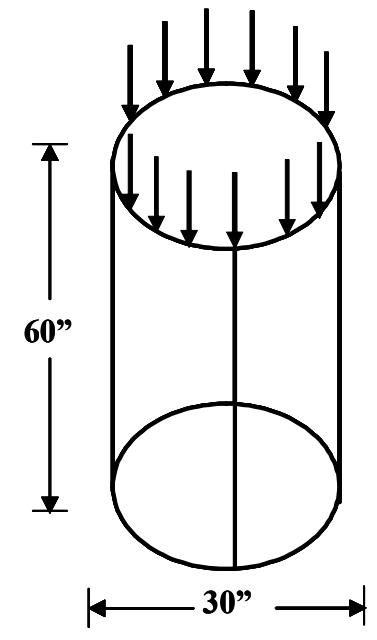

Material and Loading Configurations

- Graphite Epoxy: $\left[(45,-45,0,90)_{7},-45,45\right]$

- Ply thickness: 0.005"

- Total thickness: $0.15^{\prime \prime}$

- Fiber volume ratio: 0.65

- Void volume ratio: 0.05

- Time step for dynamic analysis: $0.00025 \mathrm{sec}$

- Total time considered for dynamic analysis: $0.05 \mathrm{sec}$

- 20 Kips dynamic load is applied in equal increment.

- Buckling analysis is performed at the end of each time step using updated deformed geometry.

Figure 1. Buckling of a Clamped-Clamped Composite Shell Subject to Dynamic Compressive Axial Loading 


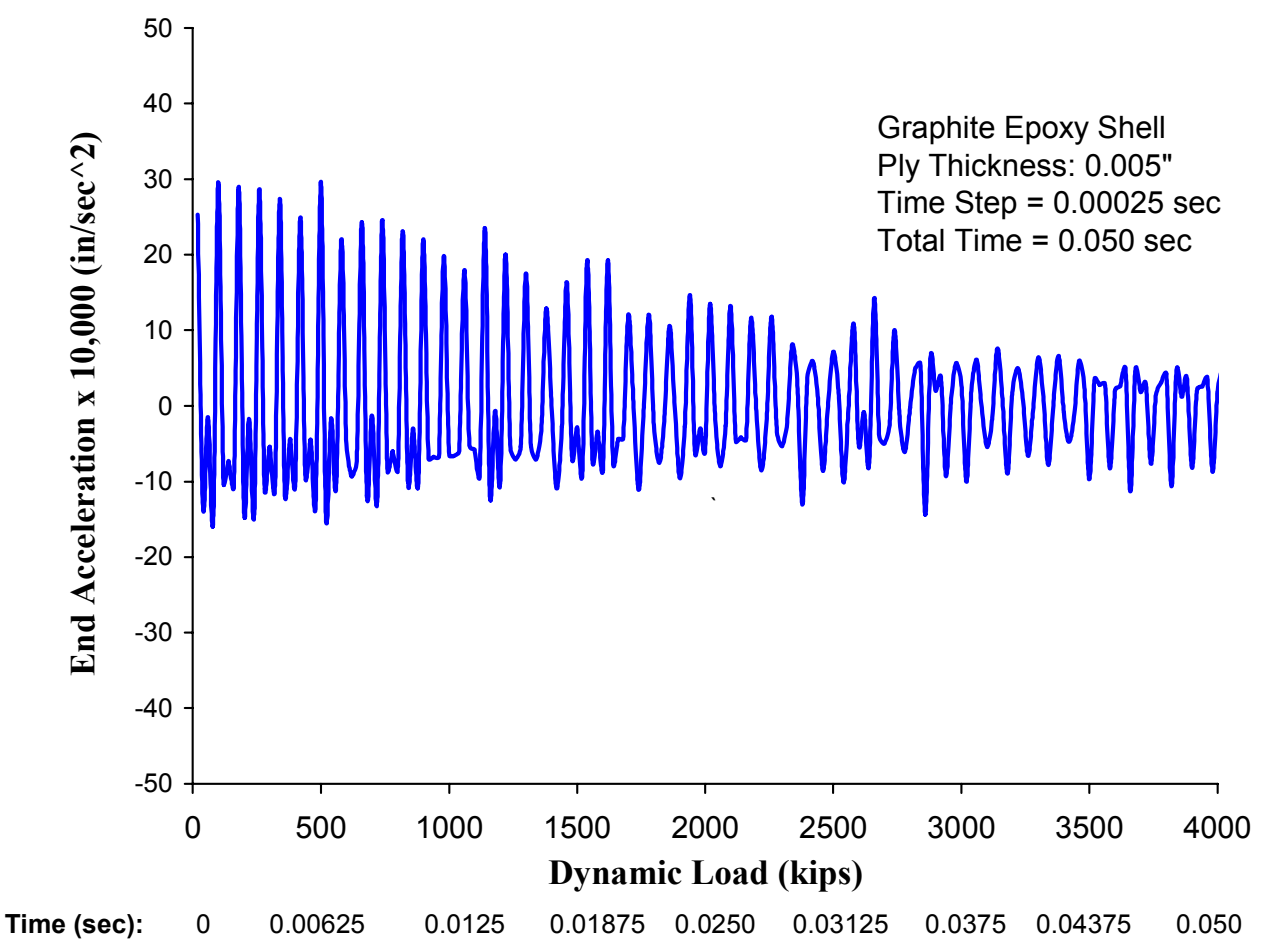

Figure 2. End Acceleration of a Composite Shell Due to Dynamic Compressive Loading

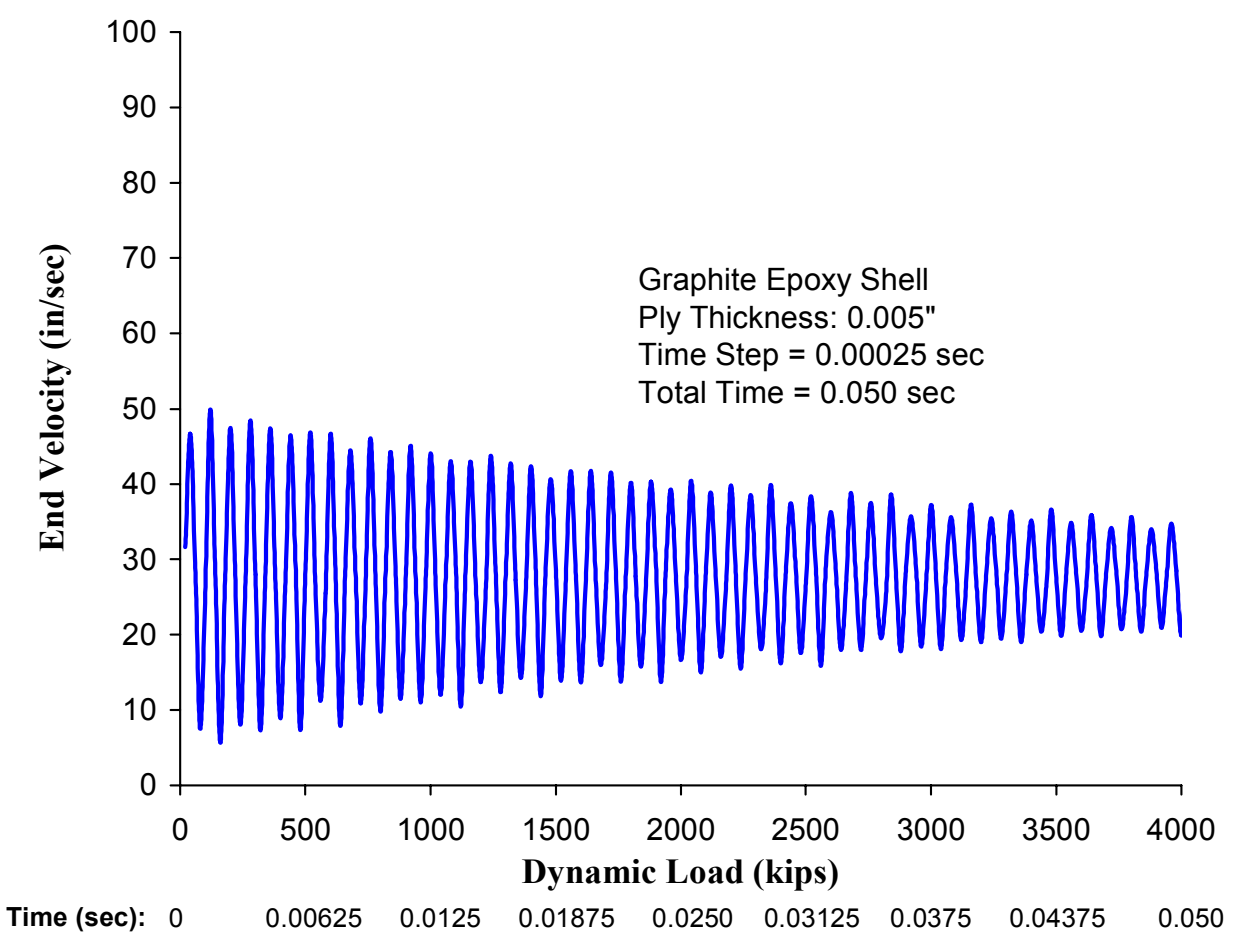

Figure 3. End Velocity of a Composite Shell Due to Dynamic Compressive Loading 


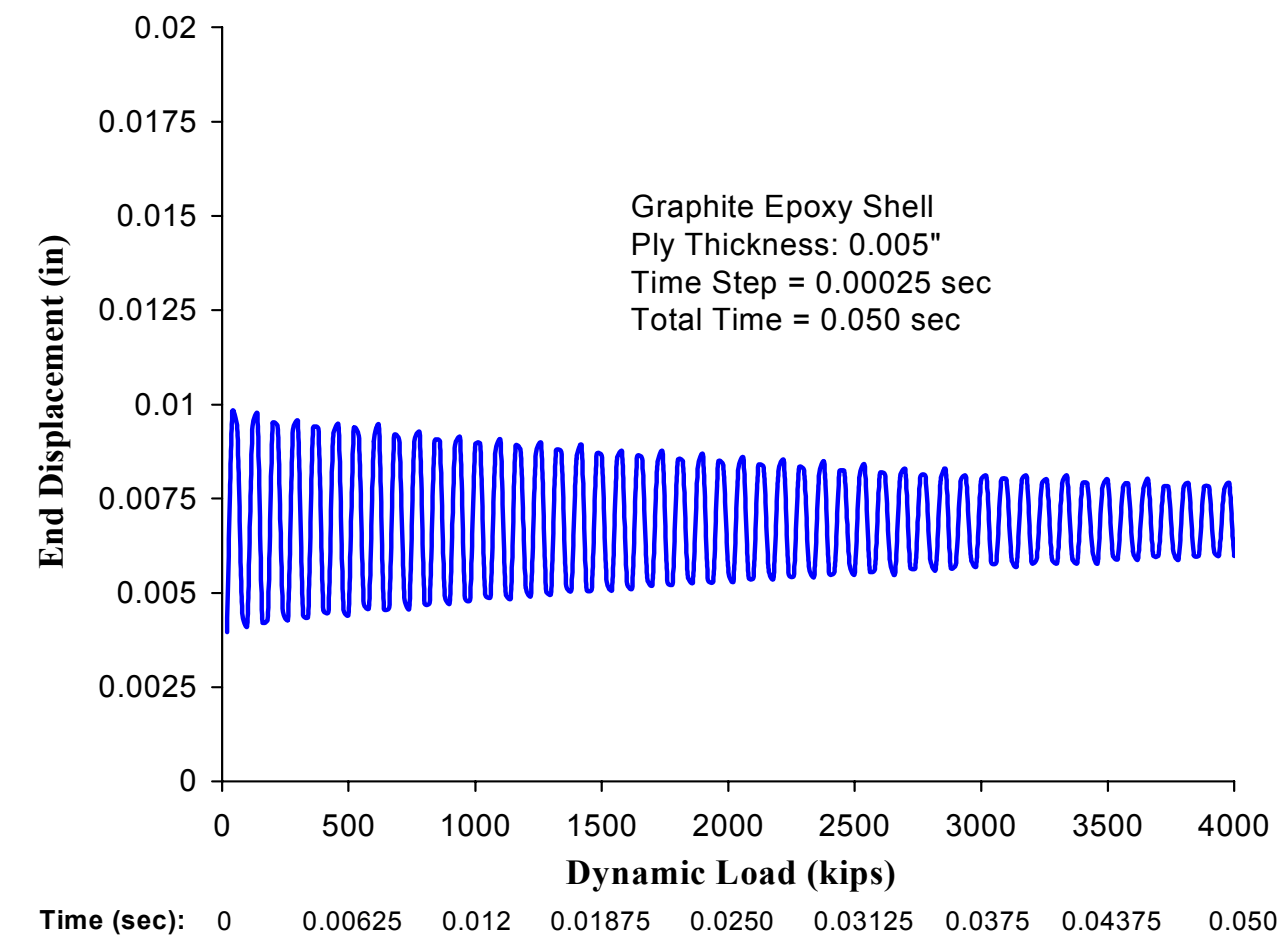

Figure 4. End Displacement of a Composite Shell Due to Dynamic Compressive Loading

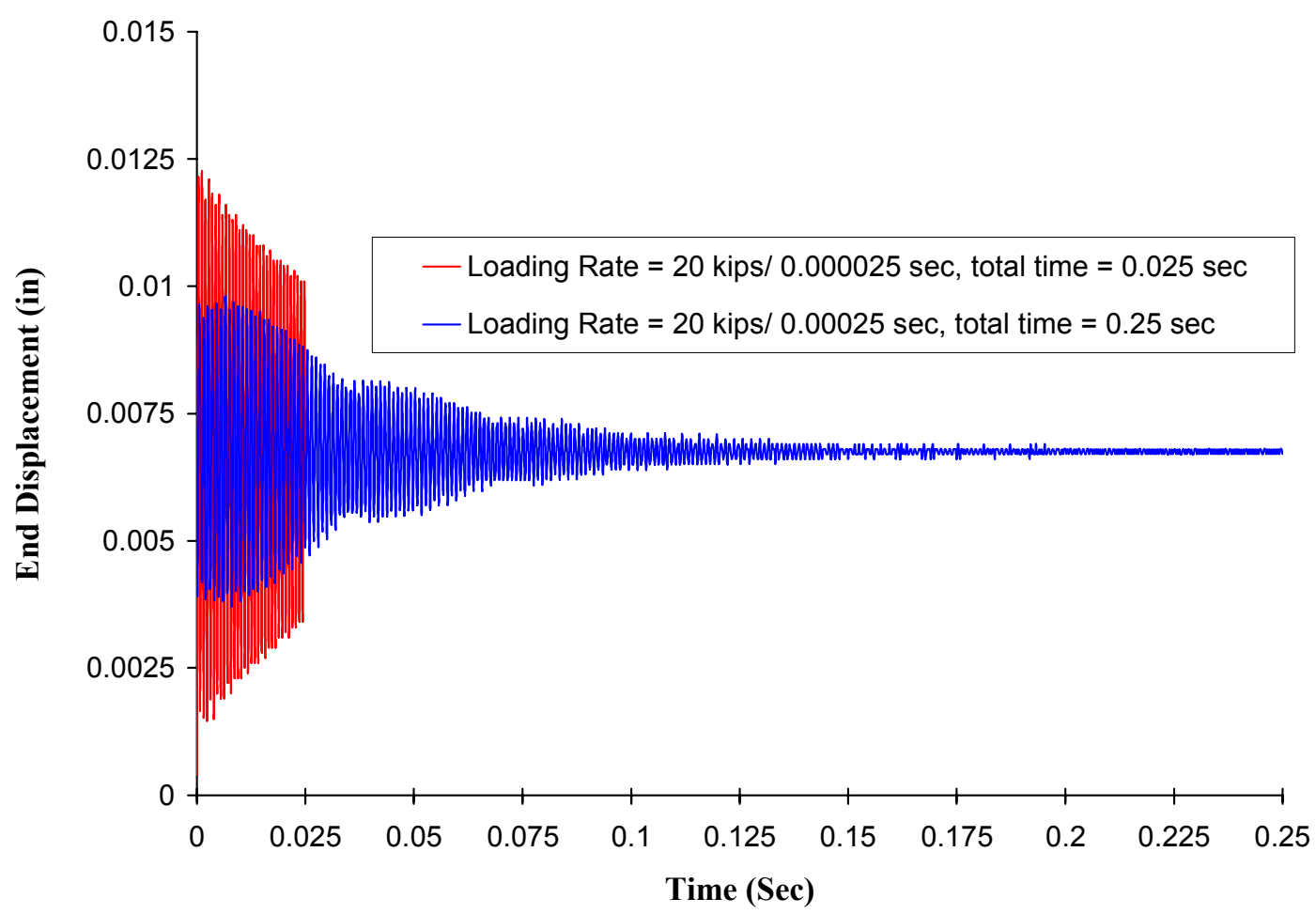

Figure 5. Effect of Loading Rate on the Incremental End Displacement of a Composite Shell 


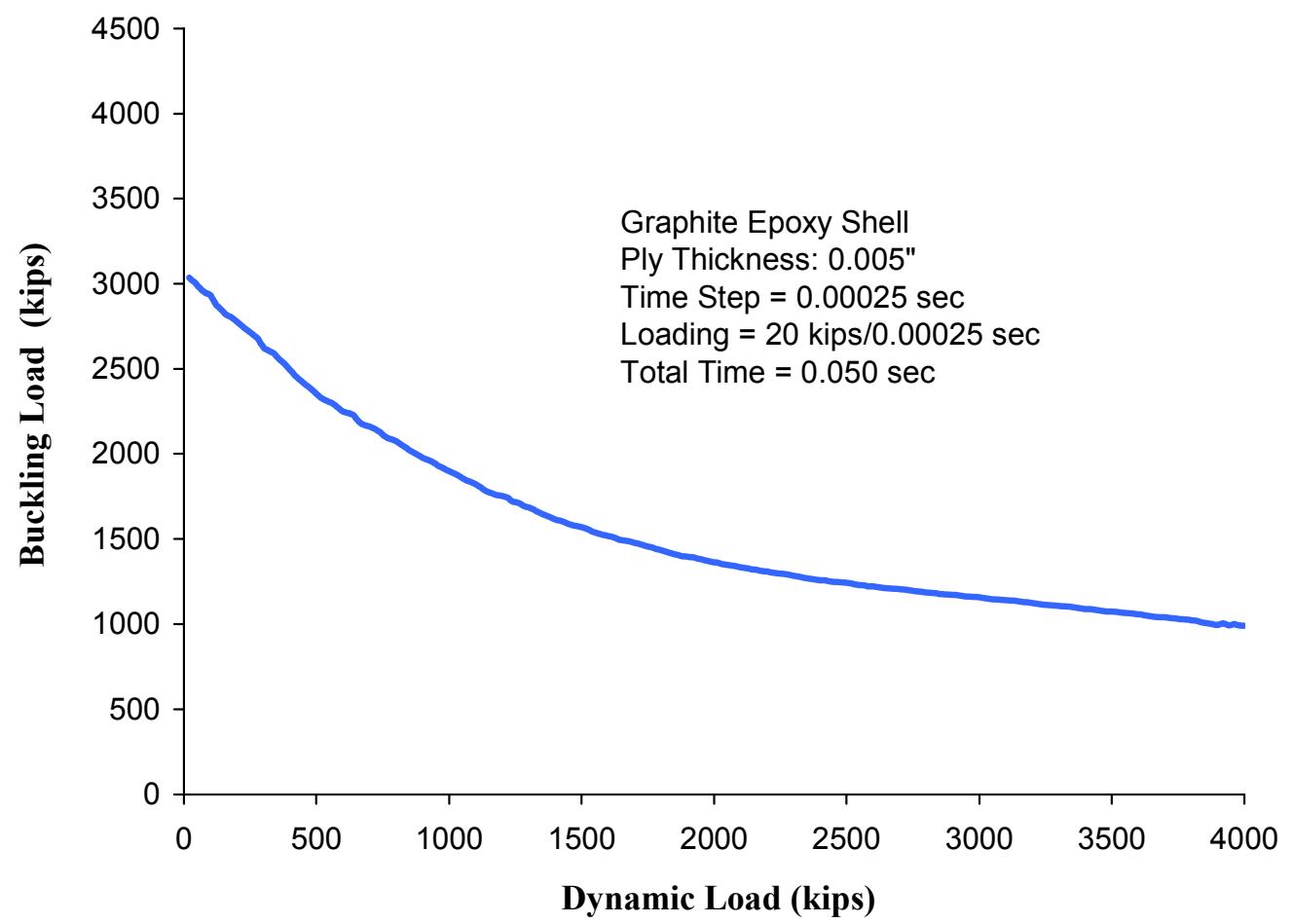

Figure 6. Effect of Dynamic Load on the Buckling Load of a Composite Shell

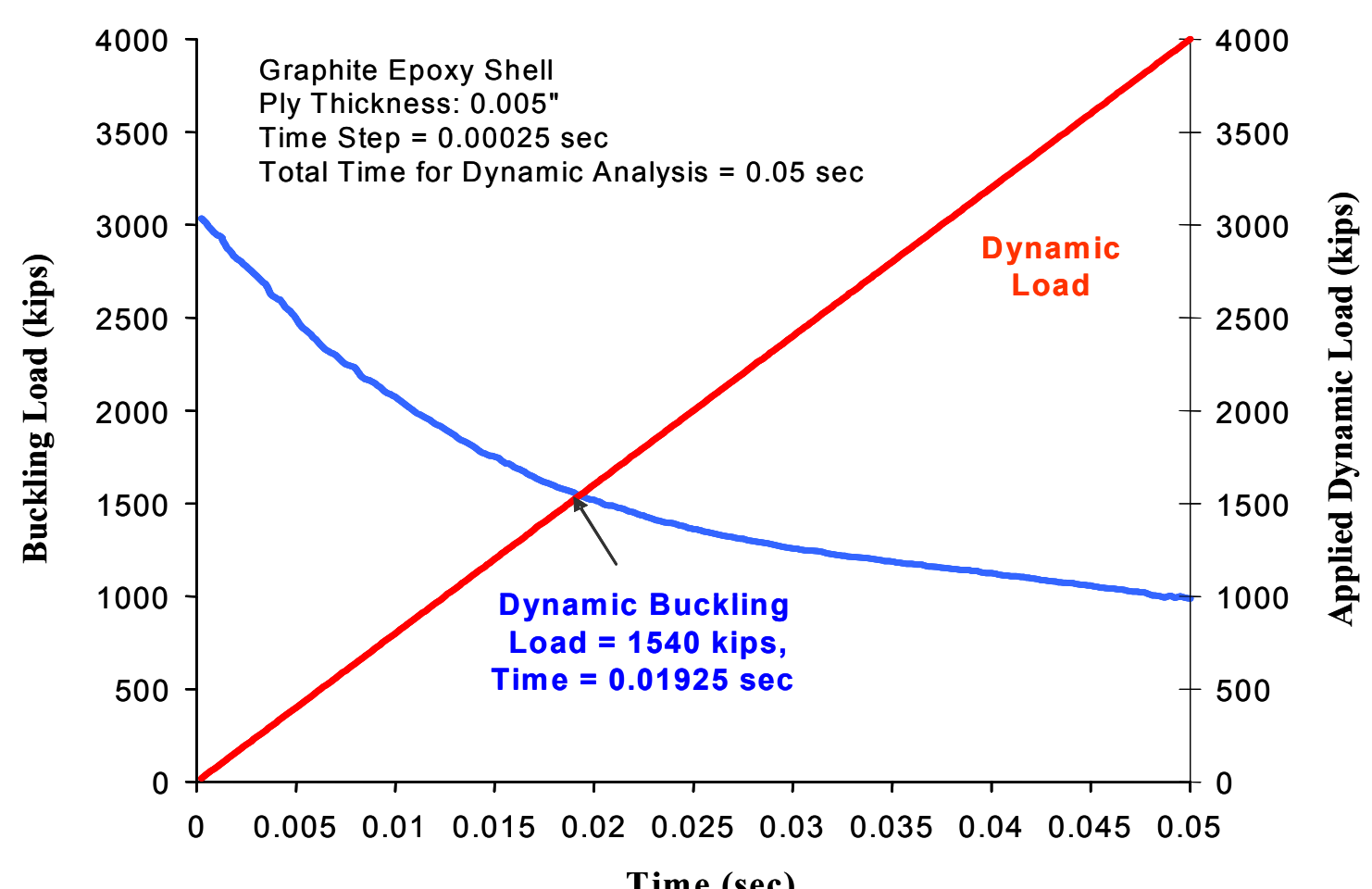

Figure 7. Effect of Time on the Buckling Load and Applied Dynamic Load (Composite Shell with Dynamic Compressive Axial Loading) 


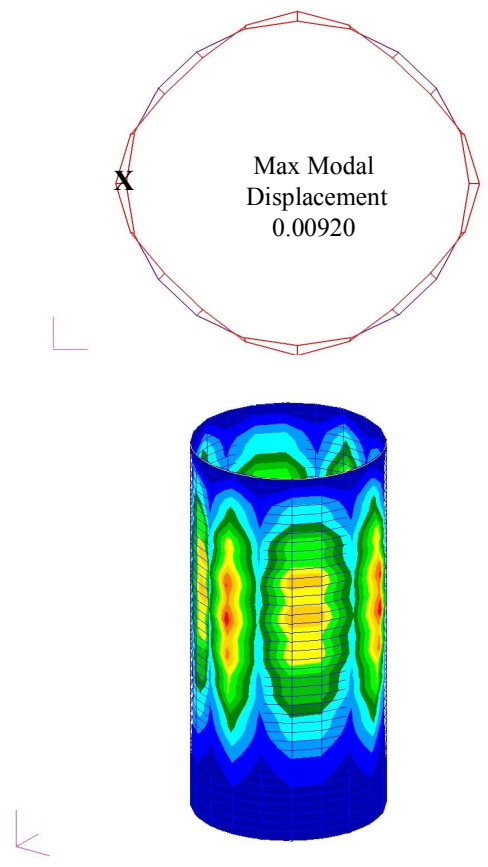

a) Static Buckling Buckling Load $=3044$ kips
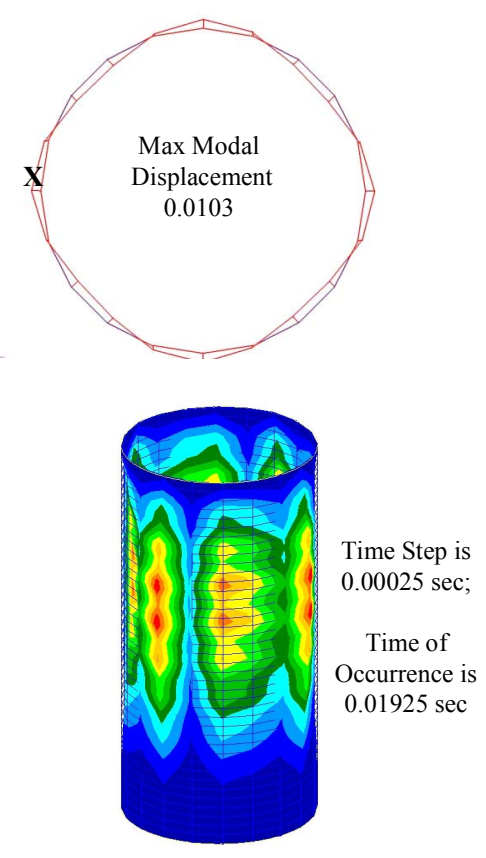

b) Dynamic Buckling Buckling Load $=1540$ kips

Figure 8. First Buckling Mode Shape of a Composite Shell - Static and Dynamic (With Compressive Axial Loading)

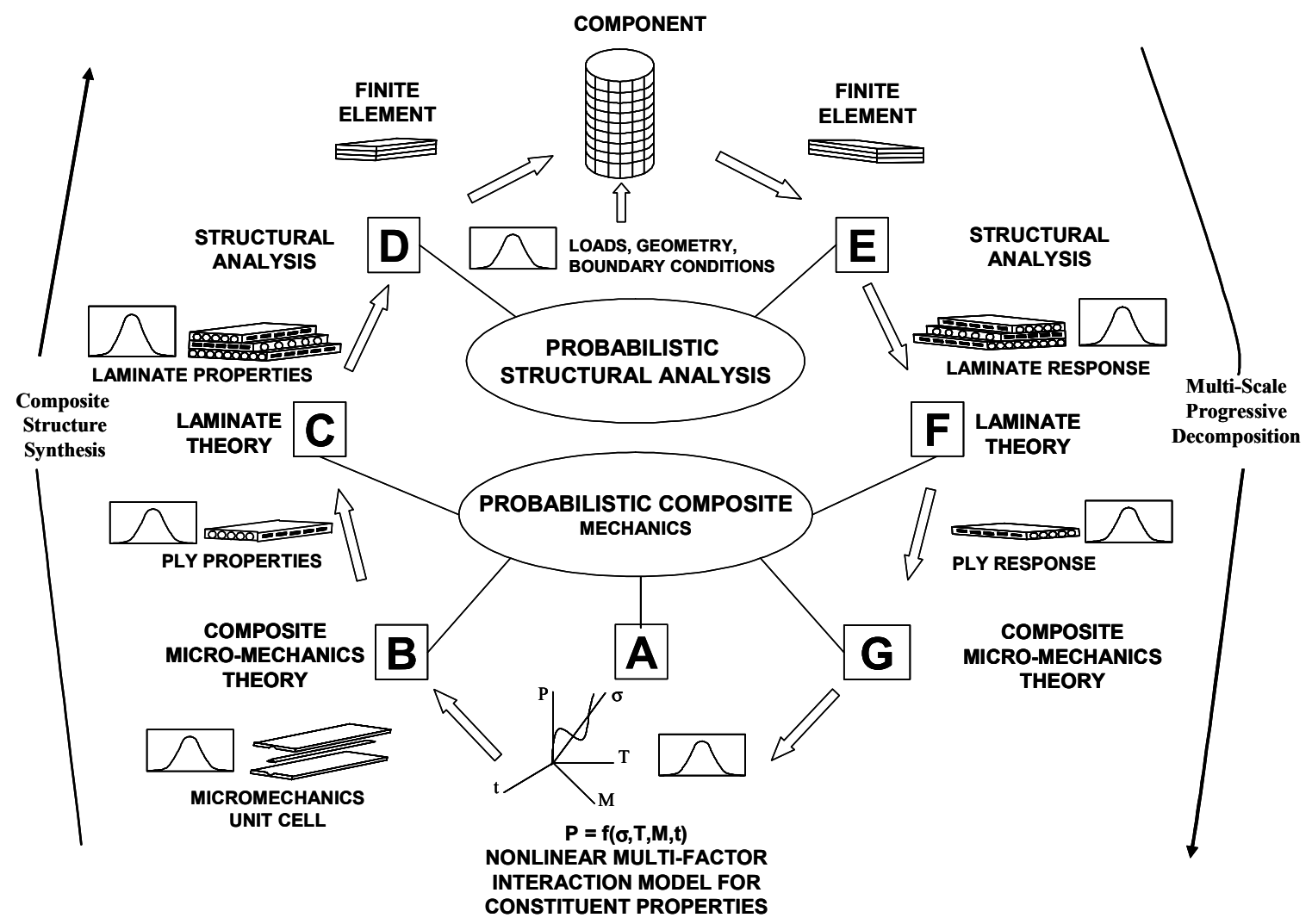

Figure 9. Modular Chart for the IPACS Computer Code 


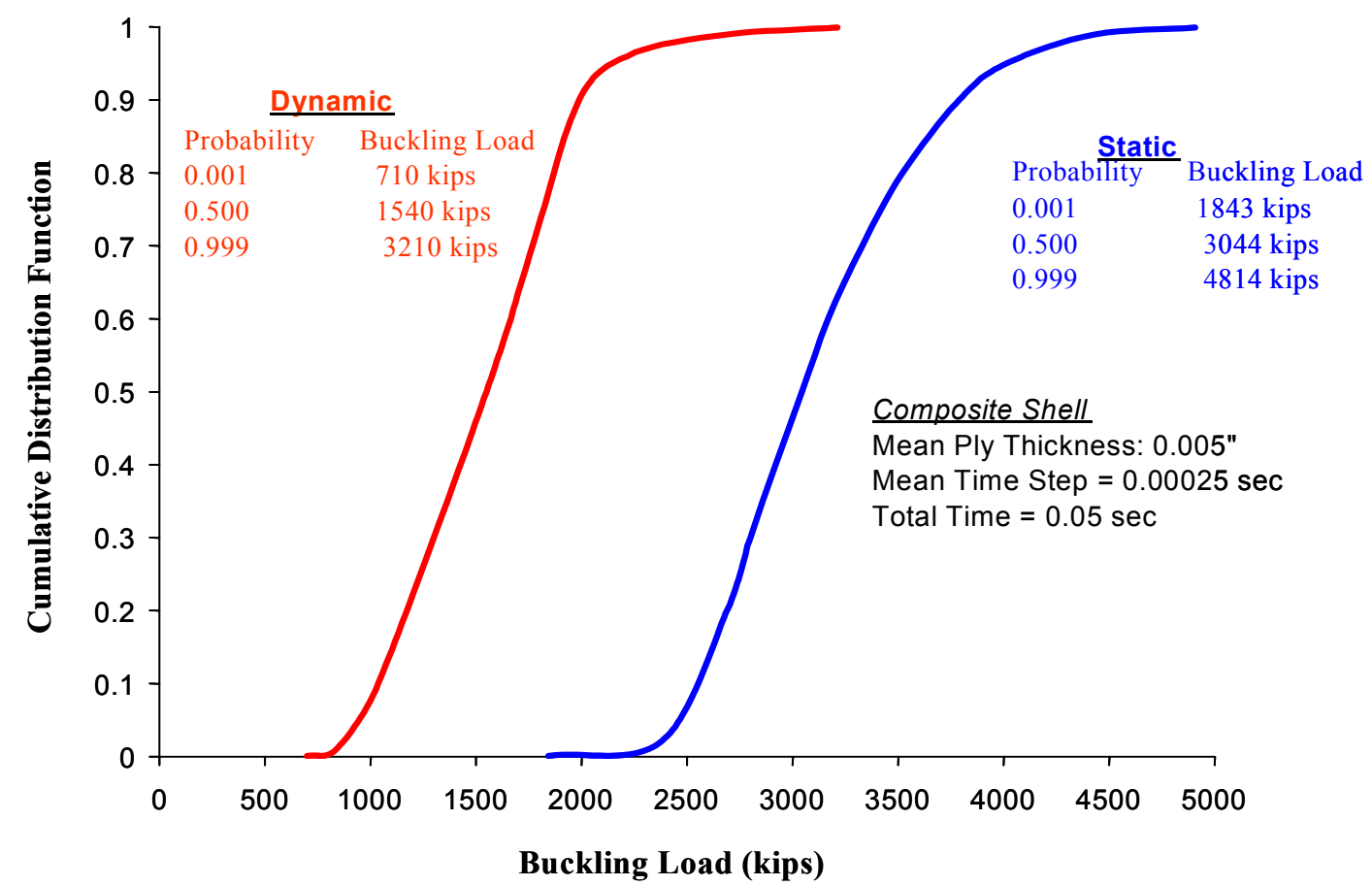

Figure 10. Probabilistic Evaluation of Static and Dynamic Buckling Loads of a Composite Shell

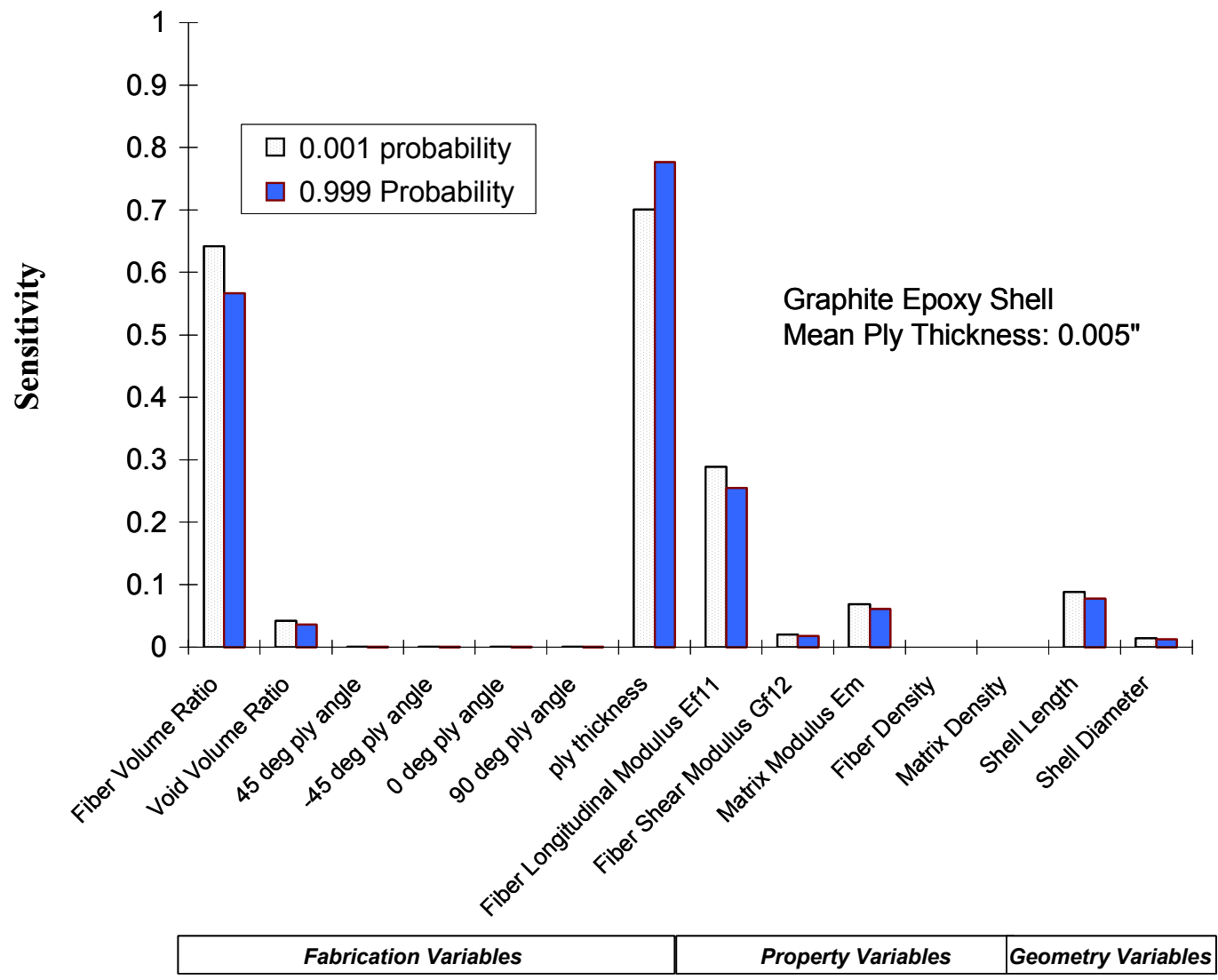

Figure 11. Probabilistic Sensitivities of the Buckling Load of a Composite Shell - Static 


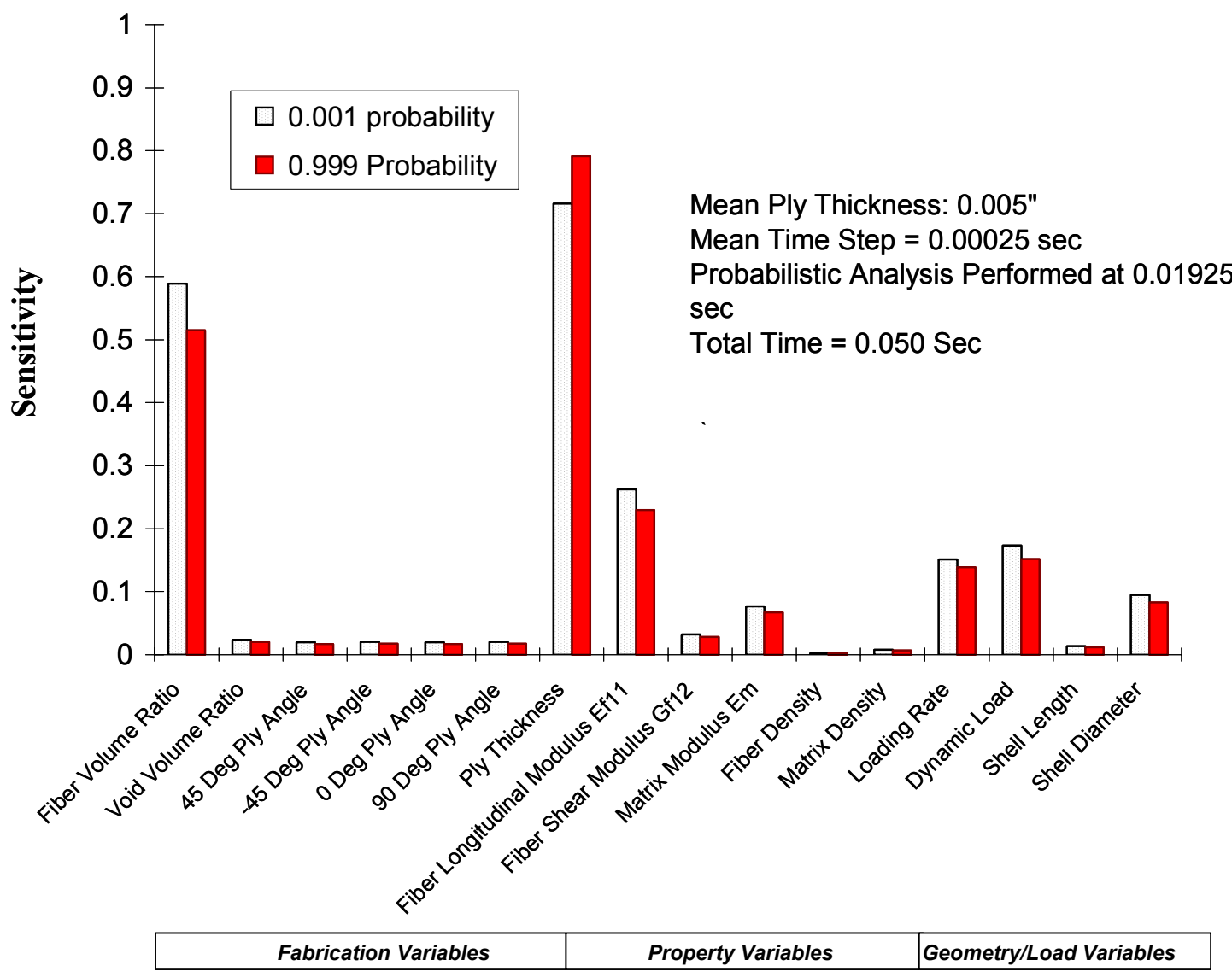

Figure 12. Probabilistic Sensitivities of the Buckling Load of a Composite Shell - Dynamic

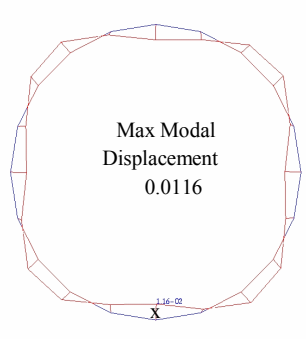

Time Step $=0.000243 \mathrm{sec}$

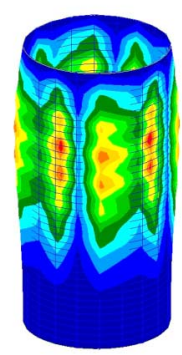

a) Under Dynamic Load (Prob $=0.001)$ Buckling Load $=710$ kips

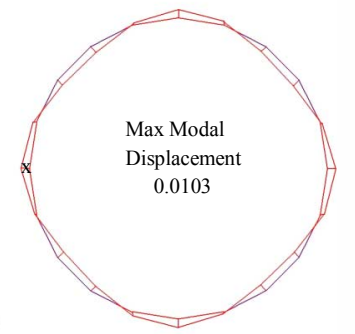

Time Step $=0.000250 \mathrm{sec}$

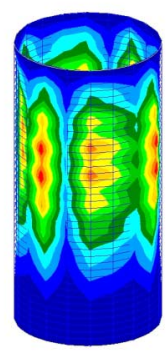

b) Under Dynamic Load (Prob $=0.50)$ Buckling Load $=1540$ kips

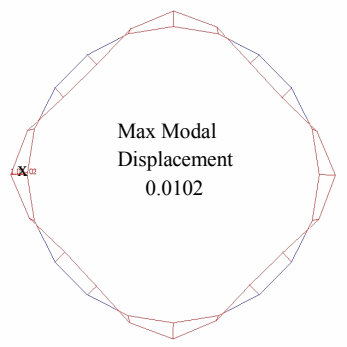

Time Step $=0.000255 \mathrm{sec}$

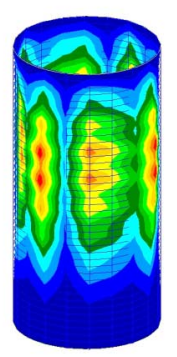

c) Under Dynamic Load (Prob $=0.999$ ) Buckling Load $=3210$ kips

Figure 13. First Buckling Mode Shape of a Composite Shell - Probabilistic Dynamic (With Compressive Axial Loading - Time of Occurrence 0.01925 sec, Total Time =0.05) 


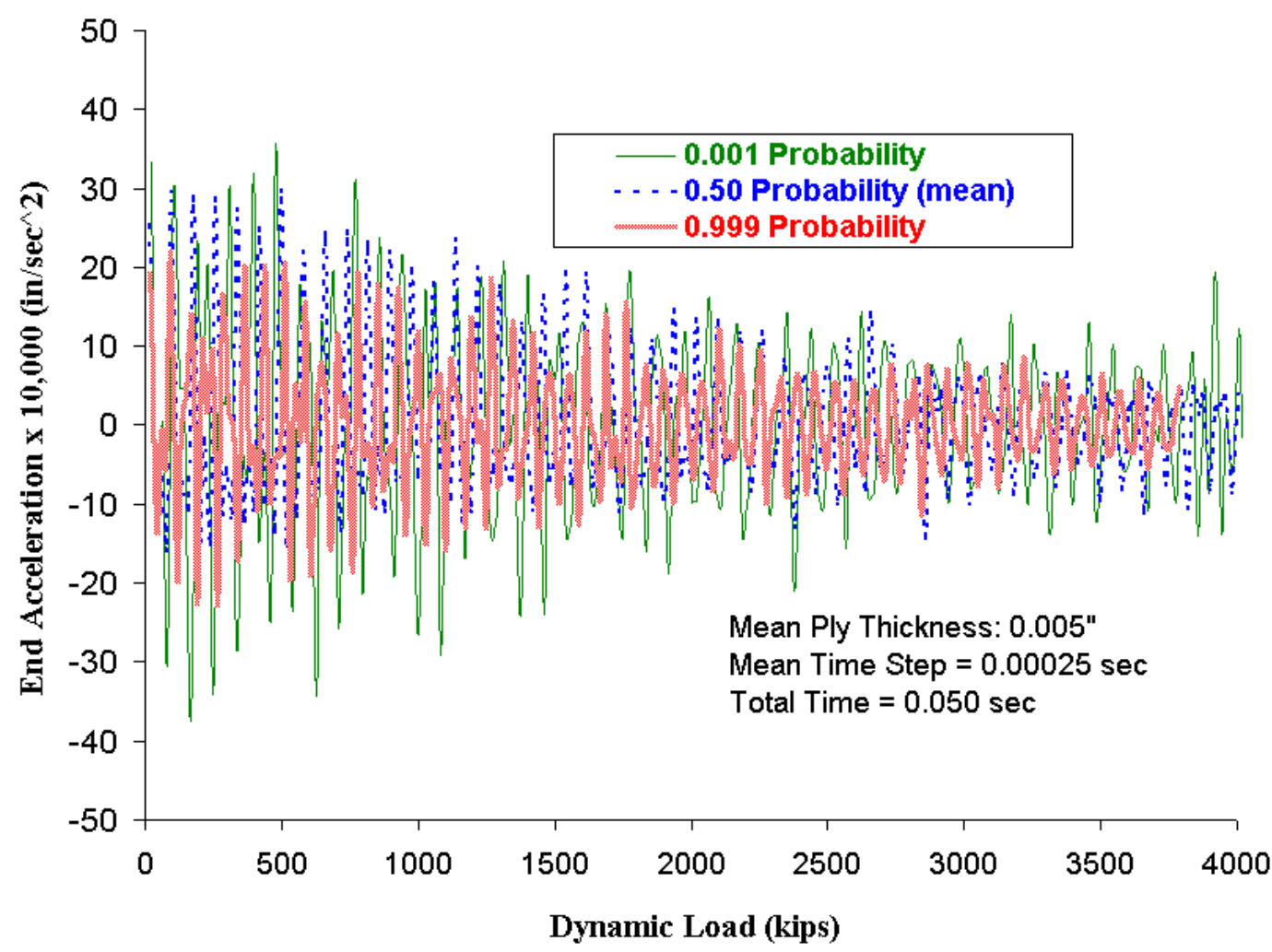

Figure 14. Probabilistic End Acceleration of a Composite Shell (With Dynamic Loading)

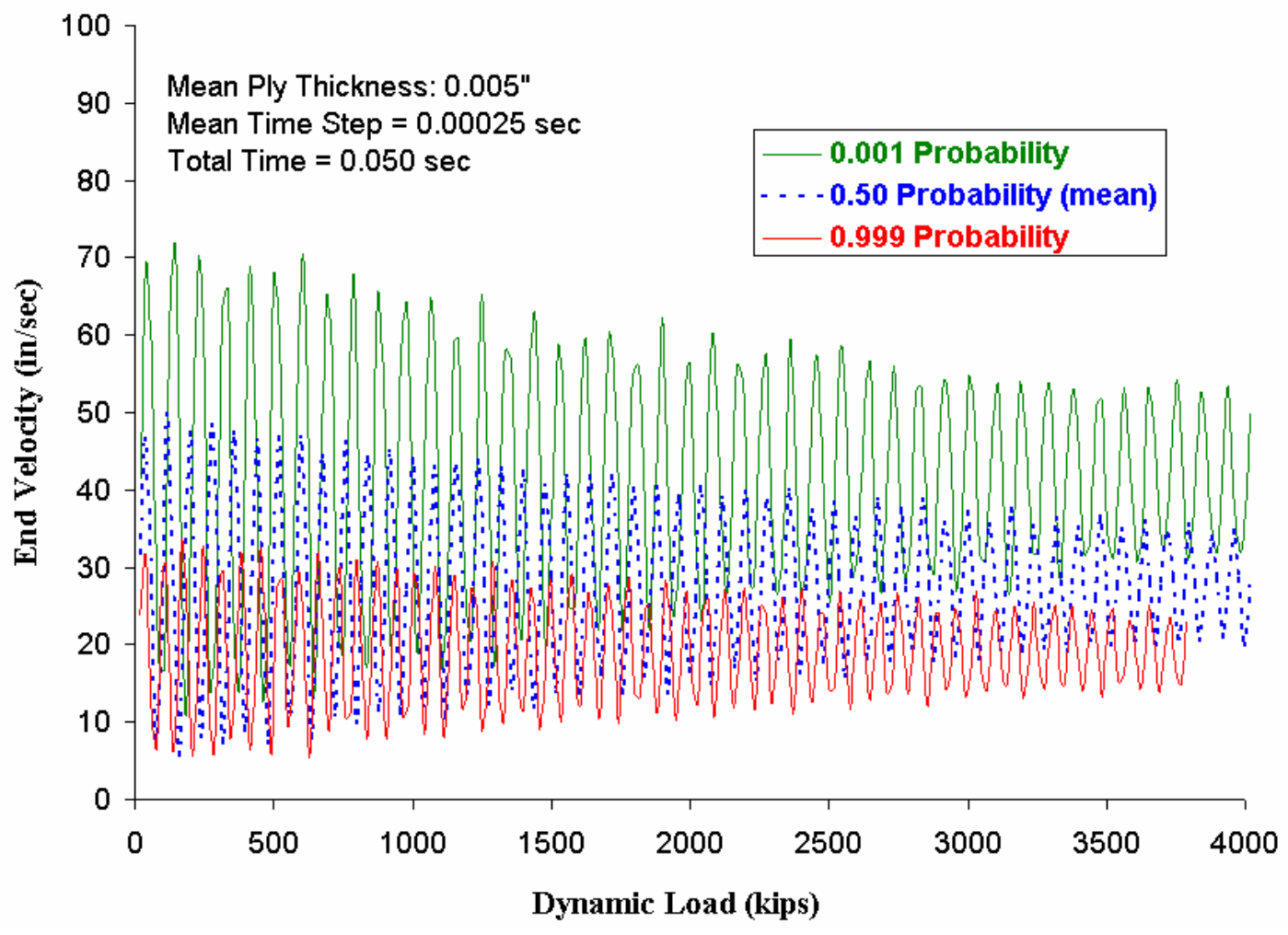

Figure 15. Probabilistic End Velocity of a Composite Shell (With Dynamic Loading) 


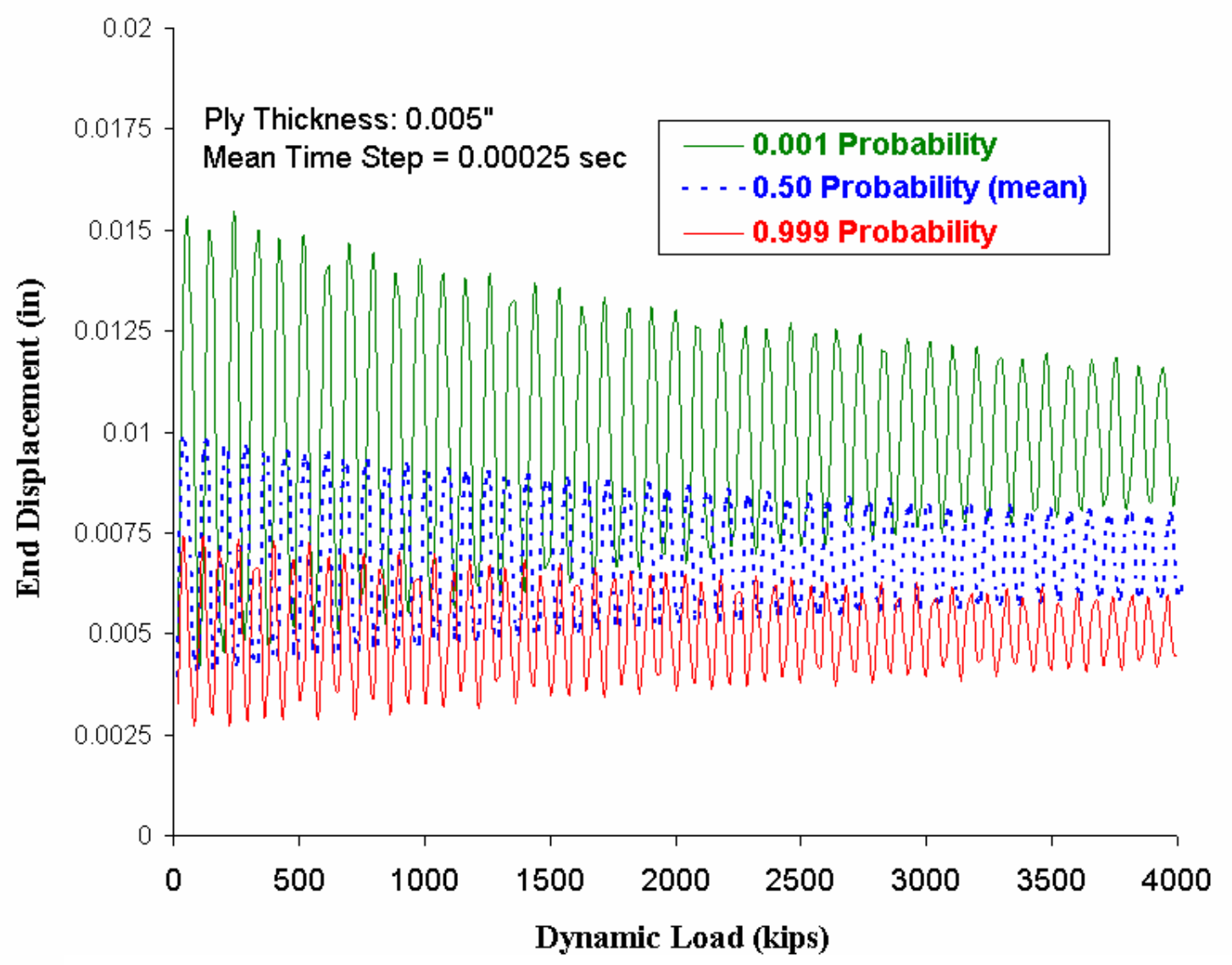

Figure 16. Probabilistic End Displacement of a Composite Shell (With Dynamic Loading)

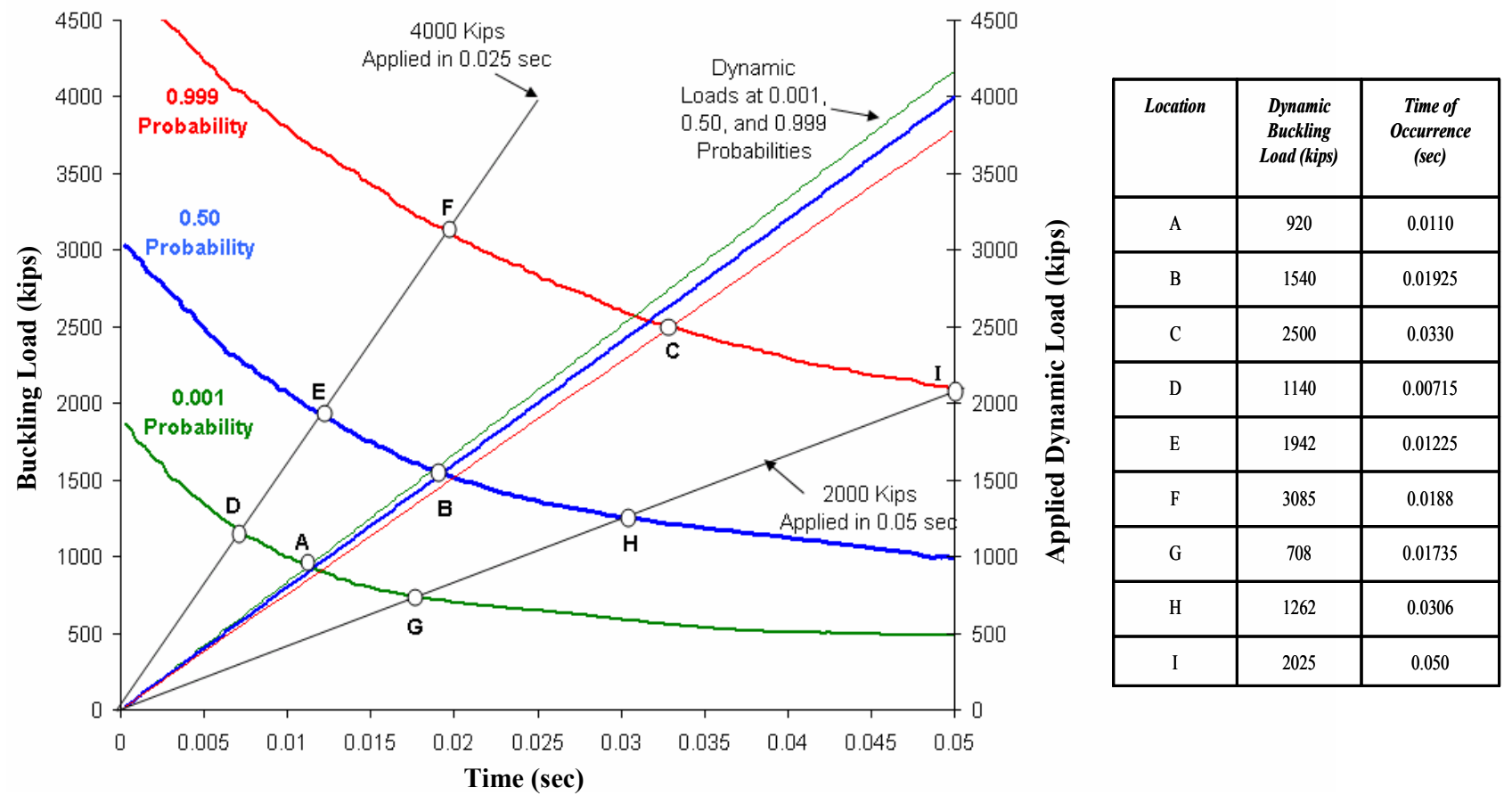

Figure 17. Graphical Estimation of the Probabilistic Dynamic Buckling Load of a Composite Shell 


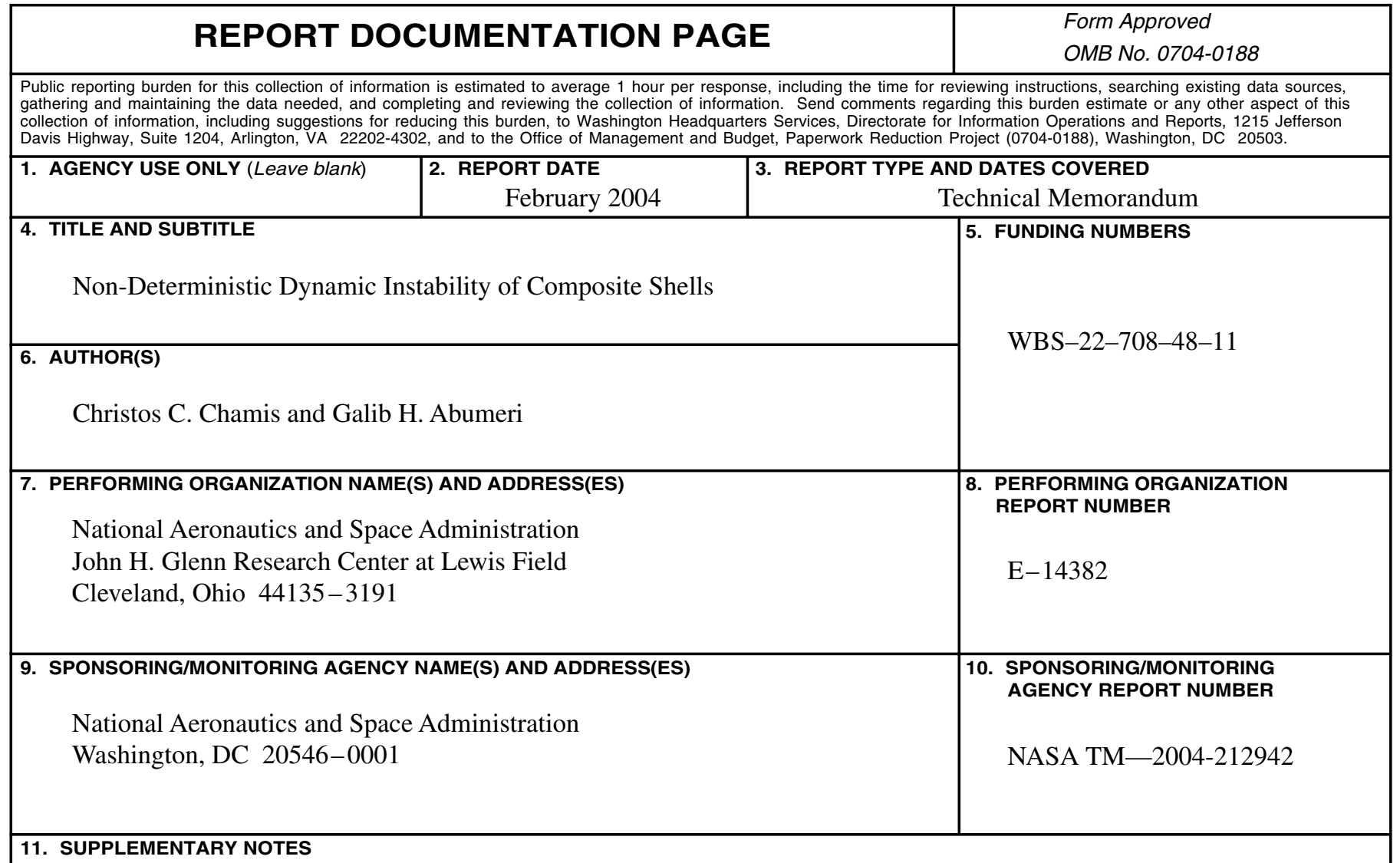

Prepared for the 44th Structures, Structural Dynamics, and Materials Conference cosponsored by the AIAA, ASME, ASCE, and AHS, Norfolk, Virginia, April 7-10, 2003. Christos C. Chamis, NASA Glenn Research Center; and Galib H. Abumeri, QSS Group, Inc., Cleveland, Ohio 44135. Responsible person, Christos C. Chamis, organization code 5000, 216-433-3252.

12a. DISTRIBUTION/AVAILABILITY STATEMENT

12b. DISTRIBUTION CODE

Unclassified - Unlimited

Subject Category: 39

Distribution: Nonstandard

Available electronically at http://gltrs.grc.nasa.gov

This publication is available from the NASA Center for AeroSpace Information, 301-621-0390.

13. ABSTRACT (Maximum 200 words)

A computationally effective method is described to evaluate the non-deterministic dynamic instability (probabilistic dynamic buckling) of thin composite shells. The method is a judicious combination of available computer codes for finite element, composite mechanics, and probabilistic structural analysis. The solution method is incrementally updated Lagrangian. It is illustrated by applying it to thin composite cylindrical shell subjected to dynamic loads. Both deterministic and probabilistic buckling loads are evaluated to demonstrate the effectiveness of the method. A universal plot is obtained for the specific shell that can be used to approximate buckling loads for different load rates and different probability levels. Results from this plot show that the faster the rate, the higher the buckling load and the shorter the time. The lower the probability, the lower is the buckling load for a specific time. Probabilistic sensitivity results show that the ply thickness, the fiber volume ratio and the fiber longitudinal modulus, dynamic load and loading rate are the dominant uncertainties, in that order.

14. SUBJECT TERMS 15. NUMBER OF PAGES

Finite element; Updating; Non-linear; Finite element analysis; Dynamic buckling; Nondeterministic dynamic buckling; Composite structures

\begin{tabular}{|c|c|c|}
\hline $\begin{array}{c}\text { 17. SECURITY CLASSIFICATION } \\
\text { OF REPORT } \\
\text { Unclassified }\end{array}$ & $\begin{array}{c}\text { 18. SECURITY CLASSIFICATION } \\
\text { OF THIS PAGE } \\
\text { Unclassified }\end{array}$ & $\begin{array}{c}\text { 19. SECURITY CLASSIFICATION } \\
\text { OF ABSTRACT } \\
\text { Unclassified }\end{array}$ \\
\hline
\end{tabular}

